Check for updates

Cite this: Phys. Chem. Chem. Phys., 2018, 20, 25052

Received 29th May 2018, Accepted 29th August 2018

DOI: $10.1039 / c 8 c p 03390 k$

rsc.li/pccp

\section{Systematic analysis of electron energy-loss near-edge structures in Li-ion battery materials $\dagger$}

\author{
Motofumi Saitoh, (D) $\ddagger^{a}$ Xiang Gao, $\ddagger^{a}$ Takafumi Ogawa, (D) ${ }^{a}$ Yumi H. Ikuhara, (D) ${ }^{a}$ \\ Shunsuke Kobayashi, (D) ${ }^{a}$ Craig A. J. Fisher, (D) a Akihide Kuwabara ${ }^{a b}$ and \\ Yuichi lkuhara*ac
}

\begin{abstract}
Electrical conductivity, state of charge and chemical stability of Li-ion battery materials all depend on the electronic states of their component atoms, and tools for measuring these reliably are needed for advanced materials analysis and design. Here we report a systematic investigation of electron energyloss near-edge structures (ELNES) of Li-K and O-K edges for ten representative Li-ion battery electrodes and solid-state electrolytes obtained by performing transmission electron microscopy with a Wien-filter monochromator-equipped microscope. While the peaks of $\mathrm{Li}-\mathrm{K}$ edges are positioned at about $62 \mathrm{eV}$ for most of the materials examined, the peak positions of $\mathrm{O}-\mathrm{K}$ edges vary within a range of about 530 to $540 \mathrm{eV}$, and the peaks can be categorised into three groups based on their characteristic edge shapes: (i) double peaks, (ii) single sharp peaks, and (iii) single broad peaks. The double peaks of group (i) are attributable to the $d^{0}$ electronic configuration of their transition metal ions bonded to $O$ atoms. The origin of the different peak shapes of groups (ii) and (iii) is more subtle but insights are gained using density functional theory methods to simulate O-K ELNES edges of group (ii) material $\mathrm{LiCoO}_{2}$ and group (iii) material $\mathrm{LiFePO}_{4}$. Comparison of their densities of states reveals that in $\mathrm{LiCoO}_{2}$ the $\mathrm{Co}-\mathrm{O}$ hybrid orbitals are separated from $\mathrm{Li}-\mathrm{O}$ hybrid orbitals, resulting in a sharp peak in the $\mathrm{O}-\mathrm{K}$ edge, while $\mathrm{Fe}-\mathrm{O}$, $\mathrm{Li}-\mathrm{O}$ and $\mathrm{P}-\mathrm{O}$ hybrid orbitals in $\mathrm{LiFePO}_{4}$ partially overlap each other and produce a broad peak.
\end{abstract}

\section{Introduction}

Li-ion batteries (LIBs) are widely used in a myriad of applications such as portable devices, electric vehicles and renewable energy storage systems. In an effort to develop superior LIBs, many candidate electrode materials have been investigated in terms of energy density, output voltage, charge-discharge rates and cycle lifetimes. ${ }^{1-3}$ At the same time, efforts to improve battery safety, compactness and stability have led to the development of solid electrolytes that exhibit good Li-ion conductivities and structural integrity after many charge-discharge cycles when used in all-solid-state LIBs. ${ }^{4}$

At the microscopic level, charging and discharging of LIBs involves diffusion of $\mathrm{Li}$ atoms, conduction of electrons and changes in valence states of the transition-metal (TM) atoms. Characterisation of the structural and chemical changes that

\footnotetext{
${ }^{a}$ Nanostructures Research Laboratory, Japan Fine Ceramics Center, Nagoya 456-8587, Japan

${ }^{b}$ National Institute for Materials Science, Tsukuba, Ibaraki 305-0047, Japan

${ }^{c}$ Institute of Engineering Innovation, The University of Tokyo, Tokyo 113-8656, Japan.E-mail: ikuhara@sigma.t.u-tokyo.ac.jp

$\dagger$ Electronic supplementary information (ESI) available. See DOI: 10.1039/c8cp03390k

\$ Authors contributed equally.
}

take place during battery operation is thus of fundamental importance in the development of improved LIB materials.

Electrodes and electrolytes in LIBs typically contain TM and Li cations bonded to anions such as $\mathrm{O}, \mathrm{S}$ and sometimes $\mathrm{F}$. Energy-loss near-edge structure (ELNES) spectra of these elements, obtained by performing electron energy-loss spectroscopy (EELS) within a transmission electron microscope (TEM), can provide useful data about their energetics and coordination environments with a spatial resolution of a few nanometres. ${ }^{5-12}$ In this work we focus on a number of actively investigated oxide LIB materials, some of whose EELS spectra have not yet been reported.

TM- $\mathrm{L}_{2,3}$ ELNES spectra, ranging over energies between 450 and $900 \mathrm{eV}$ depending on the element in question and its coordination environment, ${ }^{13}$ are widely used to characterise TM valence states because TM-L spectra change markedly when the valence state changes. ${ }^{14-16}$ Similarly, the shapes of O-K ELNES at around $530 \mathrm{eV}$ and Li-K ELNES at around $60 \mathrm{eV}$ depend strongly on the local crystal environments of these atoms and the nature of the interatomic bonding. ${ }^{11,17,18}$ In these cases, ELNES simulations using density functional theory (DFT) are indispensable for identifying the electronic transitions producing the fine structures observed experimentally. $7,11,19,20$

In the low-energy region (less than $100 \mathrm{eV}$ ) in which Li-K edges appear, high energy resolution is necessary to obtain 
peak shapes accurately. While measurements with resolutions up to $0.3 \mathrm{eV}$ (as determined by the full width half maximum (FWHM) of the zero-loss peak) can be obtained using cold-FE guns, ${ }^{21}$ to obtain resolutions better than $0.1 \mathrm{eV}$ requires use of monochromators. ${ }^{22-24}$ The latter allows Li-K edge spectra to be used to measure Li concentrations and distributions quantitatively with nanoscale resolution, as reported for materials $\mathrm{LiCoO}_{2},{ }^{25,26} \mathrm{LiFePO}_{4}{ }^{27,28}$ and $\mathrm{Li}_{2} \mathrm{MnO}_{3} \cdot{ }^{29}$ One drawback of this method, however, is that $\mathrm{TM}-\mathrm{M}_{2,3}$ (or $\mathrm{TM}-\mathrm{N}_{2,3}$ ) edges lie near to Li-K edges, making their peaks difficult to deconvolute.

Although measurements of Li-K and O-K edges of many LIB materials have been reported, ${ }^{14,15,30-36}$ to the best of our knowledge, the dependence of the ELNES spectra on the type of TM, the crystal structure, and the bonding environment has not been studied systematically. This lack of systematic comparison has sometimes led to conflicting results in the literature, and hampers deeper understanding of the relationship between electronic structure, chemical environment and electrochemical properties of these materials.

In this study, using a monochromator-equipped TEM, we carried out a systematic comparison of the effect of different TM elements and crystal environments on Li-K and O-K ELNES spectra for ten typical LIB-related materials. The structure types of each material and the coordination numbers $(\mathrm{CN})$, valence states and d-electron configurations of their component TM elements are listed in Table 1 , with representative crystal structures depicted in Fig. 1. The materials examined include six cathode materials, two solid electrolyte materials, one anode material, and one non-conductive material (as reference). The cathode materials include two layer-type materials, $\mathrm{LiCoO}_{2}$ and $\mathrm{Li}_{2} \mathrm{MnO}_{3}$; two olivine-type materials, $\mathrm{LiFePO}_{4}$ and $\mathrm{LiCoPO}_{4}$; and two spinel-type materials, $\mathrm{LiMn}_{2} \mathrm{O}_{4}$ and $\mathrm{LiNi}_{0.5} \mathrm{Mn}_{1.5} \mathrm{O}_{4}$. $\mathrm{LiCoO}_{2},{ }^{37,38}$ $\mathrm{LiMn}_{2} \mathrm{O}_{4}{ }^{39,40}$ and $\mathrm{LiFePO}_{4}{ }^{41,42}$ have been widely investigated and are used commercially. $\mathrm{Li}_{2} \mathrm{MnO}_{3}$ is a lithium-excess material with superior capacity to $\mathrm{LiCoO}_{2}$; $\mathrm{LiCoPO}_{4}$ exhibits higher output voltage than $\mathrm{LiFePO}_{4},{ }^{43,44}$ and $\mathrm{LiNi}_{0.5} \mathrm{Mn}_{1.5} \mathrm{O}_{4}$ also exhibits higher output voltage than $\mathrm{LiMn}_{2} \mathrm{O}_{4} \cdot{ }^{45,46}$ The latter three are being actively researched as next-generation cathode materials. The two

Table 1 Li-ion battery materials examined in this study, their composition, structure type, and atomic coordination numbers ( $\mathrm{CNs}$ ), together with charge states and d-electron configurations of their transition metal (TM) ions

\begin{tabular}{|c|c|c|c|c|c|c|}
\hline \multirow[b]{2}{*}{ Composition } & \multirow[b]{2}{*}{ Structure type } & \multicolumn{3}{|c|}{$\mathrm{CN}$} & \multicolumn{2}{|l|}{ TM } \\
\hline & & $\mathrm{O}$ & $\mathrm{Li}$ & TM & ion & d config. \\
\hline $\mathrm{LiFePO}_{4}$ & Olivine & 4 & 6 & 6 & $\mathrm{Fe}^{2+}$ & $\mathrm{d}^{6}(\mathrm{HS})$ \\
\hline $\mathrm{LiCoPO}_{4}$ & Olivine & 4 & 6 & 6 & $\mathrm{Co}^{2+}$ & $\mathrm{d}^{7}$ (HS) \\
\hline $\mathrm{LiCoO}_{2}$ & Layered rocksalt & 6 & 6 & 6 & $\mathrm{Co}^{3+}$ & $\mathrm{d}^{6}(\mathrm{LS})$ \\
\hline $\mathrm{Li}_{2} \mathrm{MnO}_{3}$ & Layered rocksalt & 6 & 6 & 6 & $\mathrm{Mn}^{4+}$ & $\mathrm{d}^{3}$ \\
\hline $\mathrm{LiMn}_{2} \mathrm{O}_{4}$ & Spinel & 4 & 4 & 6 & $\begin{array}{l}\mathrm{Mn}^{3+} \\
\mathrm{Mn}^{4+}\end{array}$ & $\begin{array}{l}d^{4} \\
d^{3}\end{array}$ \\
\hline $\mathrm{LiNi}_{0.5} \mathrm{Mn}_{1.5} \mathrm{O}_{4}$ & Spinel & 4 & 4 & 6 & $\begin{array}{l}\mathrm{Ni}^{2+} \\
\mathrm{Mn}^{4+}\end{array}$ & $\begin{array}{l}d^{8} \\
d^{3}\end{array}$ \\
\hline $\mathrm{Li}_{4} \mathrm{Ti}_{5} \mathrm{O}_{12}$ & Spinel & 4 & 4,6 & 6 & $\mathrm{Ti}^{4+}$ & $\mathrm{d}^{0}$ \\
\hline $\mathrm{LiNbO}_{3}$ & Trigonal perovskite & 4 & $\sim 12$ & 6 & $\mathrm{Nb}^{5+}$ & $d^{0}$ \\
\hline $\mathrm{Li}_{0.33} \mathrm{La}_{0.56} \mathrm{TiO}_{3}$ & Layered perovskite & 6 & $\sim 12$ & 6 & $\mathrm{Ti}^{4+}$ & $d^{0}$ \\
\hline $\mathrm{Li}_{0.14} \mathrm{La}_{0.29} \mathrm{NbO}_{3}$ & Layered perovskite & 6 & $\sim 12$ & 6 & $\mathrm{Nb}^{5+}$ & $d^{0}$ \\
\hline
\end{tabular}

(a)

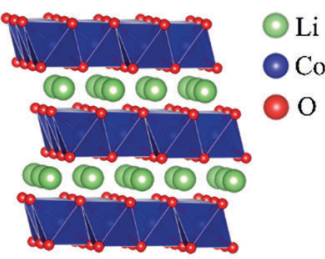

(c)

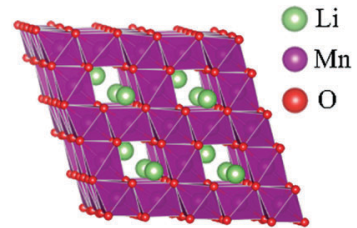

(b)

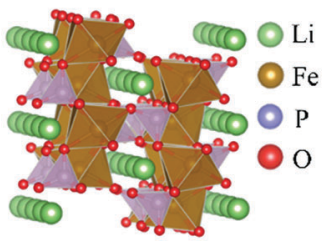

(d)

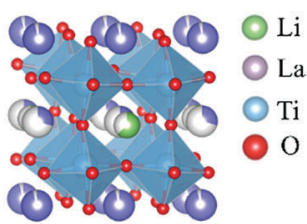

Fig. 1 Representative structures of Li-ion battery materials examined in this study: (a) $\mathrm{LiCOO}_{2}$ with layered rocksalt structure, (b) $\mathrm{LiFePO}_{4}$ with olivine structure, (c) $\mathrm{LiMn}_{2} \mathrm{O}_{4}$ with spinel structure and (d) $\mathrm{Li}_{x} \mathrm{La}_{(2-x) / 3} \mathrm{TiO}_{3}$ with layered perovskite structure. Multicoloured spheres in (d) represent partially occupied sites.

solid-state electrolytes examined were perovskite-related materials $\mathrm{Li}_{0.33} \mathrm{La}_{0.56} \mathrm{TiO}_{3}$ and $\mathrm{Li}_{0.14} \mathrm{La}_{0.29} \mathrm{NbO}_{3}$. Li site occupancy factors in these materials are low compared to the others, so $\mathrm{LiNbO}_{3}$ was also characterised as a reference material because it shares their perovskite-like structure but with fully occupied crystallographic $\mathrm{Li}$ sites. The anode material was spinel-type $\mathrm{Li}_{4} \mathrm{Ti}_{5} \mathrm{O}_{12}$.

These materials all exhibit differently shaped EELS spectra, especially in the case of O-K ELNES. To understand the origins of these differences, we carried out DFT-based calculations of $\mathrm{LiCoO}_{2}$ and $\mathrm{LiFePO}_{4}$, which exhibit representative spectrum shapes. Although several theoretical investigations have been reported for both compounds, ${ }^{20,47-49}$ the reported results are not sufficiently detailed to provide explanations for the differences in ELNES peak positions and shapes. In particular, electronic structures of excited states have not yet been reported, so in this study we performed ELNES simulations of $\mathrm{LiCoO}_{2}$ and $\mathrm{LiFePO}_{4}$ taking into account the electronic structures of the excited state, and compared the results with experimental spectra.

\section{Methods}

\subsection{Specimen preparation}

Samples of the ten compounds were prepared by different methods, as described below:

(1) $\mathrm{LiFePO}_{4}$. Powder was prepared by solid-state reaction between stoichiometric amounts of $\mathrm{Li}_{2} \mathrm{CoO}_{3}, \mathrm{FeC}_{2} \mathrm{O}_{4} \cdot 2 \mathrm{H}_{2} \mathrm{O}$ and $\left(\mathrm{NH}_{4}\right)_{2} \mathrm{HPO}_{4}$ at $600{ }^{\circ} \mathrm{C}$ for $6 \mathrm{~h}$, followed by annealing at $800{ }^{\circ} \mathrm{C}$ for $24 \mathrm{~h}$ under pure $\mathrm{Ar}$ gas flow. ${ }^{50}$

(2) LiCoPO$_{4}$. A thin film of $\mathrm{LiCoPO}_{4}$ was prepared via an aqueous sol-gel route using citric acid as the chelating agent. ${ }^{51}$ Stoichiometric amounts of $\mathrm{CH}_{3} \mathrm{COOLi}, \mathrm{Co}\left(\mathrm{NO}_{3}\right)_{2} \cdot 6 \mathrm{H}_{2} \mathrm{O}$ and $\mathrm{NH}_{4} \mathrm{H}_{2} \mathrm{PO}_{4}$ were dissolved in distilled water and citric acid was added to the solution. The precursor solution was spread on an Au-coated $\mathrm{Al}_{2} \mathrm{O}_{3}$ substrate by spin-coating and annealed first at $350{ }^{\circ} \mathrm{C}$ for $1 \mathrm{~h}$ and then at $700{ }^{\circ} \mathrm{C}$ for $1 \mathrm{~h}$. 
(3) $\mathrm{LiCoO}_{2} \cdot \mathrm{LiCoO}_{2}$ single crystals were prepared via a flux method using $\mathrm{LiCoO}_{2}, \mathrm{Li}_{2} \mathrm{O}$ and $\mathrm{LiCl}$. The mixture was heated at $900{ }^{\circ} \mathrm{C}$ for $10 \mathrm{~h}$, cooled to $700{ }^{\circ} \mathrm{C}$ at a rate of $2{ }^{\circ} \mathrm{C} \mathrm{h}^{-1}$ and then allowed to cool naturally down to room temperature. Platelet-like $\mathrm{LiCoO}_{2}$ single crystals were separated by rinsing the frozen flux in hot water.

(4) $\mathbf{L i}_{2} \mathbf{M n O}_{3} \cdot \mathrm{Li}_{2} \mathrm{MnO}_{3}$ nanocrystals were fabricated by a hydrothermal method. $\mathrm{LiOH} \cdot \mathrm{H}_{2} \mathrm{O}$ was dissolved in distilled water and $\gamma-\mathrm{MnO}_{2}$ powder was added to the solution. The mixture was heated at $180{ }^{\circ} \mathrm{C}$ for $24 \mathrm{~h}$ in an autoclave, centrifuged, washed with water and ethanol, and dried at $120{ }^{\circ} \mathrm{C}$.

(5) $\operatorname{LiMn}_{2} \mathrm{O}_{4} \cdot \mathrm{LiMn}_{2} \mathrm{O}_{4}$ thin film was fabricated by chemical solution deposition of chemically modified $\mathrm{LiOC}_{2} \mathrm{H}_{4} \mathrm{OC}_{2} \mathrm{H}_{5}$ and $\mathrm{Mn}\left(\mathrm{OC}_{2} \mathrm{H}_{4} \mathrm{OC}_{2} \mathrm{H}_{5}\right)_{4}$ solutions by refluxing in $\mathrm{C}_{2} \mathrm{H}_{5} \mathrm{OC}_{2} \mathrm{H}_{4} \mathrm{OH}{ }^{52}$ The precursor solution was spin-coated onto an $\mathrm{Au}$-coated $\mathrm{Al}_{2} \mathrm{O}_{3}$ substrate to form a thin film after heat treatment at $750{ }^{\circ} \mathrm{C}$ for $1 \mathrm{~h}$.

(6) $\mathbf{L i N i}_{0.5} \mathbf{M n}_{1.5} \mathrm{O}_{4} \cdot \mathrm{LiNi}_{0.5} \mathrm{Mn}_{1.5} \mathrm{O}_{4}$ polycrystalline powder was prepared by a sol-gel method. $\mathrm{LiCH}_{3} \mathrm{COO} \cdot 2 \mathrm{H}_{2} \mathrm{O}$, $\mathrm{Mn}\left(\mathrm{CH}_{3} \mathrm{COO}\right)_{2} \cdot 4 \mathrm{H}_{2} \mathrm{O}, \mathrm{Ni}\left(\mathrm{CH}_{3} \mathrm{COO}\right)_{2} \cdot 4 \mathrm{H}_{2} \mathrm{O}$ and glycolic acid were dissolved in distilled water and gelated. After calcining the precursor gel at $250{ }^{\circ} \mathrm{C}$ for $1 \mathrm{~h}$, the powder was sintered at $800{ }^{\circ} \mathrm{C}$ for $20 \mathrm{~h}$.

(7) $\quad \mathbf{L i}_{4} \mathrm{Ti}_{5} \mathbf{O}_{12} \cdot \mathrm{Li}_{4} \mathrm{Ti}_{5} \mathrm{O}_{12}$ thin film was fabricated by a sputtering method using a pristine $\mathrm{Li}_{4} \mathrm{Ti}_{5} \mathrm{O}_{12}$ target. ${ }^{53}$ The deposited film was annealed at $900{ }^{\circ} \mathrm{C}$.

(8) $\mathrm{LiNbO}_{3} \cdot \mathrm{LiNbO}_{3}$ powder was prepared by a conventional solid-state reaction method from $\mathrm{Li}_{2} \mathrm{CO}_{3}$ and $\mathrm{Nb}_{2} \mathrm{O}_{5}$ by sintering at $1000{ }^{\circ} \mathrm{C}$ for $5 \mathrm{~h} .{ }^{54}$

(9) $\mathbf{L i}_{0.33} \mathrm{La}_{0.56} \mathrm{TiO}_{3} \cdot \mathrm{Li}_{0.33} \mathrm{La}_{0.56} \mathrm{TiO}_{3}$ powder was prepared by a solid-state reaction method by sintering mixtures of $\mathrm{Li}_{2} \mathrm{CO}_{3}, \mathrm{TiO}_{2}$ and $\mathrm{La}_{2} \mathrm{O}_{3} .{ }^{55}$

(10) $\mathbf{L i}_{0.14} \mathrm{La}_{\mathbf{0 . 2 9}} \mathrm{NbO}_{3}$. A single crystal of $\mathrm{Li}_{0.14} \mathrm{La}_{0.29} \mathrm{NbO}_{3}$ was fabricated by a conventional unidirectional solidification method. ${ }^{54} \mathrm{LiNbO}_{3}$ and $\mathrm{LaNb}_{3} \mathrm{O}_{9}$ precursor powders were mixed, compacted into a cylindrical shape and sintered at $1200{ }^{\circ} \mathrm{C}$ for $20 \mathrm{~h}$. The sintered polycrystalline $\mathrm{Li}_{0.14} \mathrm{La}_{0.29} \mathrm{NbO}_{3}$ rod that resulted was melted in a Pt crucible at $1380{ }^{\circ} \mathrm{C}$ and then gradually passed downward through a unidirectional solidification furnace.

X-ray diffraction measurements were used to confirm that materials (1) to (10) were each prepared successfully as a single phase with the appropriate crystal structure under ambient conditions (see Fig. S1 in ESI $\dagger$ ).

\subsection{EELS measurements}

TEM specimens of thin films of $\mathrm{LiCoPO}_{4}, \mathrm{LiMn}_{2} \mathrm{O}_{4}$ and $\mathrm{Li}_{4} \mathrm{Ti}_{5} \mathrm{O}_{12}$ were prepared using low-temperature (liquid $\mathrm{N}_{2}$-cooled to below $-100{ }^{\circ} \mathrm{C}$ ) and low-voltage $(3.0 \mathrm{kV}$ to $0.2 \mathrm{kV})$ ion-milling (PIPS, Gatan Inc.). Special care was taken to minimise damage to the samples, and surfaces were cleaned using a plasma cleaner (Solarus, Gatan Inc.) to remove residual amorphous phases. TEM specimens of the other bulk samples were prepared by careful crushing, and the resulting powders dispersed and deposited onto lacey carbon films (above copper substrates).
EELS measurements were carried out using a JEM-2400FCS atomic resolution microscope (JEOL Ltd.) equipped with a spherical-aberration corrector (CEOS GmbH), an EELS spectrometer (GIF Tridiem ERS, Gatan Inc.) and a Wien-filter type monochromator. The microscope was installed in a room designed and constructed to minimise AC magnetic fields, floor vibrations, air-flow volume, temperature fluctuations and acoustic vibrations. In this stable environment, a high energy resolution below $30 \mathrm{meV}$ was achieved. ${ }^{24}$

EELS spectra were recorded with an accelerating voltage of $60 \mathrm{kV}$ to reduce irradiation damage and a convergence/collection semi-angle of $30 / 35 \mathrm{mrad}$. The energy resolution, $\Delta E$, specified in terms of the FWHM of the zero-loss peak, was controlled by changing the width of an energy selection slit in the monochromator. To examine the effect of energy resolution on ELNES spectra, we measured Li-K edges of $\mathrm{LiFePO}_{4}, \mathrm{LiCoPO}_{4}, \mathrm{LiCoO}_{2}$ and $\mathrm{Li}_{4} \mathrm{Ti}_{5} \mathrm{O}_{12}$ under various slit conditions, viz., no slit, slit of width $4 \mu \mathrm{m}$, and slit of width $1 \mu \mathrm{m}$, keeping the dispersion value constant at $0.05 \mathrm{eV}$ per pixel. The resulting $\Delta E$ were $0.7 \mathrm{eV}, 0.35 \mathrm{eV}$ and $0.1 \mathrm{eV}$, respectively.

Measurements to compare Li-K edges of all materials were performed using a dispersion value, slit width, and measurement exposure time of $0.05 \mathrm{eV}$ per pixel, $1 \mu \mathrm{m}$ and $0.2 \mathrm{~s}$, respectively. Similarly, for O-K edges, values of $0.1 \mathrm{eV}$ per pixel, $4 \mu \mathrm{m}$ and $1 \mathrm{~s}$, respectively, were used. The dispersion value of $0.1 \mathrm{eV}$ per pixel used for O-K edge measurements was larger than that for Li-K edges, but is comparable to the natural line width of the $\mathrm{O}-\mathrm{K}$ edge, $0.12 \mathrm{eV}{ }^{56}$ These conditions provided resolutions of $\Delta E=0.1$ and $0.3 \mathrm{eV}$ for Li-K and $\mathrm{O}-\mathrm{K}$ edges, respectively. Integration times per measurement for both edges were 10-20 s. Energy alignment was carried out by measuring the zero-loss peak just before and after recording edge spectra. The standard deviation of the zero-loss peak position was $0.03 \mathrm{eV}$ over a time span of 10 minutes (see Fig. S2 in ESI $\dagger$ ).

\subsection{ELNES simulations}

Theoretical O-K ELNES spectra of $\mathrm{LiCoO}_{2}$ and $\mathrm{LiFePO}_{4}$ were generated from first-principles calculations using the $\mathrm{DFT}+U$ method including spin polarisation. ${ }^{57}$ In all calculations, the GGA-PBE functional was used for the exchange-correlation term. ${ }^{58}$ Values of $U$ of $4.91 \mathrm{eV}$ and $3.71 \mathrm{eV}$, respectively, were applied to d electrons in $\mathrm{Co}^{3+}$ in $\mathrm{LiCoO}_{2}$ and $\mathrm{Fe}^{2+}$ in $\mathrm{LiFePO}_{4}{ }^{59}$ In $\mathrm{LiFePO}_{4}$, although the most stable spin configuration is antiferromagnetic, the temperature of the anti-ferromagnetic-toferromagnetic transition is below room temperature, ${ }^{49}$ so we assumed $\mathrm{LiFePO}_{4}$ to be in the ferromagnetic state for the calculations.

Before generating ELNES spectra, lattice parameters of $\mathrm{LiCoO}_{2}$ and $\mathrm{LiFePO}_{4}$ were determined by performing structural optimisation using the VASP $\operatorname{code}^{60}$ with a planewave cut-off energy of $500 \mathrm{eV}$. The hexagonal $R \overline{3} \mathrm{~m}$ unit cell (12 atoms) of $\mathrm{LiCoO}_{2}$ was optimised using a $15 \times 15 \times 3$ Brillouin zone $\boldsymbol{k}$-point mesh, and the orthorhombic Pnma unit cell (28 atoms) of $\mathrm{LiFePO}_{4}$ using a $6 \times 9 \times 15 \mathrm{k}$-point mesh.

O-K ELNES spectra were generated using the core-hole method implemented in the WIEN2k code with an all-electron 
basis set (APW + lo method). ${ }^{61}$ In this method, the transition probabilities were calculated using a supercell with an electron removed from the 1 s orbital of an $\mathrm{O}$ atom (core hole) and placed in the conduction band. ${ }^{62}$ According to the spin selection rule, we need to consider the probability of each spin state of the excited electron. In the case of an up-spin excited electron, only up-spin orbitals are relevant to the transition calculation, and vice versa for down-spin excited electrons. Because $\mathrm{LiCoO}_{2}$ in its ground state is non-magnetic, the probabilities of up-spin excitation and down-spin excitation are identical, so we only performed calculations for an up-spin excitation. In the case of $\mathrm{LiFePO}_{4}$, although up- and down-spin excitations are not equivalent, our test calculations revealed that the differences between the two excited states are small. The theoretical ELNES spectra of $\mathrm{LiFePO}_{4}$ reported here were generated by averaging contributions of up- and down-spin orbitals from calculation of a down-spin excitation.

Muffin tin radii $\left(R_{\mathrm{MT}}\right)$ for $\mathrm{Li}, \mathrm{O}, \mathrm{P}, \mathrm{Co}$ and Fe were $1.70,1.60$ $\left(\mathrm{LiCoO}_{2}\right) / 1.45\left(\mathrm{LiFePO}_{4}\right), 1.45,2.00$ and $2.10 \mathrm{bohr}$, respectively. The cutoff parameter that determines the maximum wave number of plane waves, $R_{k_{\max }}$, was set at 7.0, and O-1s states were treated as core levels for both $\mathrm{LiCoO}_{2}$ and $\mathrm{LiFePO}_{4}$. A $4 \times 4 \times 1$ (192 atom) supercell was constructed from the $\mathrm{LiCoO}_{2}$ unit cell and a $1 \times 2 \times 2$ (112 atom) supercell from the $\mathrm{LiFePO}_{4}$ unit cell, with $3 \times 3 \times 2$ and $4 \times 3 \times 3 \boldsymbol{k}$-point meshes, respectively, for integrating over the Brillouin zone. In $\mathrm{LiFePO}_{4}$, as there are three non-equivalent $\mathrm{O}$ sites, we calculated the contribution of each type of $\mathrm{O}$ separately and took the weighted average when calculating the projected density of states (PDOS) of O-p orbitals and ELNES spectra. The core level of the most distant $\mathrm{O}$ atom from the excited $\mathrm{O}$ atom in each supercell was used as reference to adjust the PDOS position. The transition energy obtained from the difference in total energies between ground and excited states was used to adjust ELNES edge positions.

\section{Results and discussion}

\subsection{Effect of energy resolution on Li-K ELNES}

The effect of different energy resolutions, i.e., $\Delta E=0.7,0.35$ and $0.1 \mathrm{eV}$, on EELS spectra in the low-loss region around Li-K edges was examined for $\mathrm{LiFePO}_{4}, \mathrm{LiCoPO}_{4}, \mathrm{LiCoO}_{2}$ and $\mathrm{Li}_{4} \mathrm{Ti}_{5} \mathrm{O}_{12}$ (Fig. 2). As can be seen in Fig. 2(c) and (d), the positions and shapes of the strongest peaks change little with $\Delta E$ in the cases of $\mathrm{Li}_{4} \mathrm{Ti}_{5} \mathrm{O}_{12}$ and $\mathrm{LiCoO}_{2}$. In the case of $\mathrm{LiCoPO}_{4}$, when $\Delta E=$ $0.35 \mathrm{eV}$, a small trough appears at higher energy than the largest peak, around $64 \mathrm{eV}$, and when $\Delta E=0.1 \mathrm{eV}$, small peaks appear on both sides of this trough as indicated by the blue arrow in Fig. 2(b). The splitting of the peak on the left side of the trough from the largest peak is accompanied by a shift of the largest peak to slightly lower energy, allowing the edge position to be determined with higher accuracy. In the case of $\mathrm{LiFePO}_{4}$, the single peak at $58.2 \mathrm{eV}$ apparent when $\Delta E=0.7 \mathrm{eV}$ changes into a main peak and shoulder peak at 57.6 and $58.3 \mathrm{eV}$, respectively, when $\Delta E=0.1 \mathrm{eV}$, as indicated by the red arrows in Fig. 2(a).
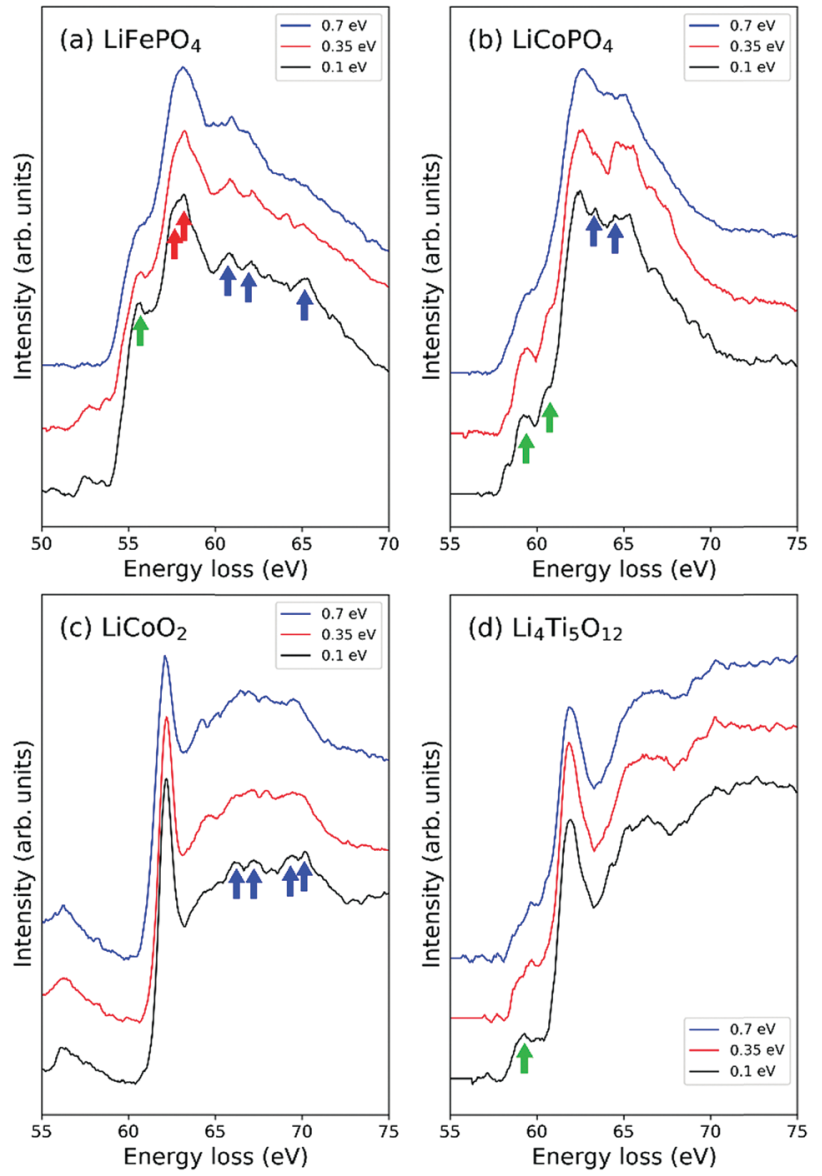

Fig. $2 \mathrm{Li}-\mathrm{K}$ edges of EELS spectra using energy resolutions, $\Delta E$, of 0.7 , 0.35 and $0.1 \mathrm{eV}$ for (a) $\mathrm{LiFePO}_{4}$, (b) $\mathrm{LiCoPO}_{4}$, (c) $\mathrm{LiCoO}_{2}$ and (d) $\mathrm{Li}_{4} \mathrm{Ti}_{5} \mathrm{O}_{12}$. Fine structures emerging when an energy resolution of $0.1 \mathrm{eV}$ is used are indicated by arrows. Green arrows indicate pre-edge peaks, blue arrows indicate post-edge peaks and red arrows indicate splitting of main edges.

In the cases of $\mathrm{LiFePO}_{4}, \mathrm{LiCoPO}_{4}$ and $\mathrm{Li}_{4} \mathrm{Ti}_{5} \mathrm{O}_{12}$, pre-edge peaks become more distinct with decreasing $\Delta E$ as indicated by green arrows in Fig. 2(a), (b) and (d). In $\mathrm{LiCoO}_{2}$ and $\mathrm{LiFePO}_{4}$ small bumps appear in the tails of the largest peaks at higher energies when $\Delta E \leq 0.35 \mathrm{eV}$, as indicated by blue arrows in Fig. 2(a) and (c). Although such peaks are small, they are useful for checking the accuracy of calculated spectra. For example, the spectral shape including tail peaks of $\mathrm{LiCoO}_{2}$ has been verified by DFT calculations using the $Z+1$ method by Kikkawa et al. ${ }^{30}$ In the case of $\mathrm{LiFePO}_{4}$, while the largest peak in Fig. 2(a) at around $58 \mathrm{eV}$ corresponds to the $\mathrm{Fe}-\mathrm{M}_{2,3}$ edge, the peaks above $60 \mathrm{eV}$ indicated by the blue arrows are thought to be components of the Li-K edge because it has been reported that the intensities of these peaks decrease with decreasing $\mathrm{Li}$ content. ${ }^{32}$ In this case, performing EELS measurements with high resolution becomes critically important as such features may otherwise be missed.

\subsection{Comparison of Li-K ELNES}

Fig. 3(a) shows experimentally obtained ELNES spectra for all materials measured with a resolution of $\Delta E=0.1 \mathrm{eV}$. The main 
peak positions of $\mathrm{TM}-\mathrm{M}_{2,3}$ ( or $\mathrm{N}_{2,3}$ for $\mathrm{Nb}$ ) edges and Li-K edges are indicated by grey and black inverted triangles, respectively. The weak peaks assumed to be Li-K edges in the spectra of $\mathrm{Li}_{0.14} \mathrm{La}_{0.29} \mathrm{NbO}_{3}$ and $\mathrm{Li}_{0.33} \mathrm{La}_{0.56} \mathrm{TiO}_{3}$ are indicated by open inverted triangles. Fig. 3(b) shows a magnified view of the energy region around the Li-K edges after background subtraction. TM- $\mathrm{M}_{2,3}$ (or $\mathrm{N}_{2,3}$ for $\mathrm{Nb}$ ) edges have also been subtracted, except for the Fe-M $\mathrm{M}_{2,3}$ edge for $\mathrm{LiFePO}_{4}$. Table 2 compares these peak positions with data available in the literature. ${ }^{13,14,30,32-34,36}$ Agreement to within $1 \mathrm{eV}$ was obtained in all cases.

TM- $\mathrm{M}_{2,3}\left(\mathrm{Nb}-\mathrm{N}_{2,3}\right)$ edges are known to correspond to transitions from $3 \mathrm{p}_{3 / 2,1 / 2}$ (or $4 \mathrm{p}_{3 / 2,1 / 2}$ ) core states to the unoccupied conduction bands. A systematic comparison of the spectra reveals peak positions shift to higher energies as the atomic number increases. This trend reflects the shift to lower core energy levels with increasing atomic number.

In $\mathrm{LiNi}_{0.5} \mathrm{Mn}_{1.5} \mathrm{O}_{4}, \mathrm{LiFePO}_{4}, \mathrm{LiCoPO}_{4}$ and $\mathrm{LiCoO}_{2}$, the $\mathrm{M}_{2,3}$ edges of $\mathrm{Ni}, \mathrm{Fe}$ and $\mathrm{Co}$ are close to and partially overlap the Li-K edges, complicating detection of the latter. As mentioned in the previous section, in the case of $\mathrm{LiFePO}_{4}$, we cannot assign the weak protrusion at around $62 \mathrm{eV}$ to the $\mathrm{Li}-\mathrm{K}$ edge without comparison with measurements from delithiated samples. Similarly, the Li-K edge in $\mathrm{LiCoO}_{2}$ has been identified by comparison with spectra from delithiated samples. ${ }^{30}$ In the case of $\mathrm{LiCoPO}_{4}$, no such data are available, so we here assume
Table 2 Peak positions of TM-M,N and Li-K edges compared with data in the literature. Values obtained by background subtraction are given in parentheses

\begin{tabular}{|c|c|c|c|c|}
\hline \multirow[b]{2}{*}{ Composition } & \multicolumn{2}{|c|}{ TM-M,N edges (eV) } & \multicolumn{2}{|c|}{ Li-K edge $(\mathrm{eV})$} \\
\hline & This work & Previous work & This work & Previous work \\
\hline $\mathrm{LiFePO}_{4}$ & $55.9,58.3$ & $55.5,57.4^{a}$ & 60.9 & $60.3^{a}$ \\
\hline $\mathrm{LiCoPO}_{4}$ & - & & 62.4 & $63.0^{e}$ \\
\hline $\mathrm{LiCoO}_{2}$ & - & & 62.2 & $62.0^{f}$ \\
\hline $\mathrm{Li}_{2} \mathrm{MnO}_{3}$ & $50.0,55.5$ & $50.4,55.4^{b}$ & 61.7 & $62.6^{b}$ \\
\hline $\mathrm{LiMn}_{2} \mathrm{O}_{4}$ & $50.2,54.9$ & $49.5,54.5^{c}$ & 61.4 & $60.6^{c}$ \\
\hline $\mathrm{LiNi}_{0.5} \mathrm{Mn}_{1.5} \mathrm{O}_{4}$ & $49.7,54.6$ & & 61.2 & \\
\hline $\mathrm{Li}_{4} \mathrm{Ti}_{5} \mathrm{O}_{12}$ & $39.3,47.3$ & $39.5,47.3^{d}$ & 61.8 & $61.6^{d}$ \\
\hline $\mathrm{LiNbO}_{3}$ & $39.0,46.6$ & & 61.3 & \\
\hline $\mathrm{Li}_{0.33} \mathrm{La}_{0.56} \mathrm{TiO}_{3}$ & $39.2,47.4$ & & $(58.8)$ & $59.1^{g}$ \\
\hline $\mathrm{Li}_{0.14} \mathrm{La}_{0.29} \mathrm{NbO}_{3}$ & $38.4,46.4$ & & $(60.4)$ & \\
\hline
\end{tabular}

${ }^{a}$ Ref. 20. ${ }^{b}$ Ref. 36. ${ }^{c}$ Ref. $14 .{ }^{d}$ Ref. 33. ${ }^{e}$ Ref. 51. ${ }^{f}$ Ref. $30 .{ }^{g}$ Ref. 34.

the peak at around $62 \mathrm{eV}$ to be the Li-K edge, similar to the case for $\mathrm{LiCoO}_{2}$. The Ni-M $\mathrm{M}_{2,3}$ edge of $\mathrm{LiNi}_{0.5} \mathrm{Mn}_{1.5} \mathrm{O}_{4}$ is assumed to occur at energies higher than the Li-K edge by several electronvolts because in Ni metal it appears at $68 \mathrm{eV} .{ }^{13}$ Based on this, the small protrusion at $61.9 \mathrm{eV}$ to the right of the $\mathrm{Mn}-\mathrm{M}_{2,3}$ edges was assigned to the Li-K edge.

In the magnified spectra of $\mathrm{Li}_{0.14} \mathrm{La}_{0.29} \mathrm{NbO}_{3}$ and $\mathrm{Li}_{0.33} \mathrm{La}_{0.56}$ $\mathrm{TiO}_{3}$, very slight peaks are visible at around $60 \mathrm{eV}$. However, it is difficult to distinguish these Li-K edges from $\mathrm{Nb}-\mathrm{N}_{1}$ and $\mathrm{Ti}-\mathrm{M}_{1}$
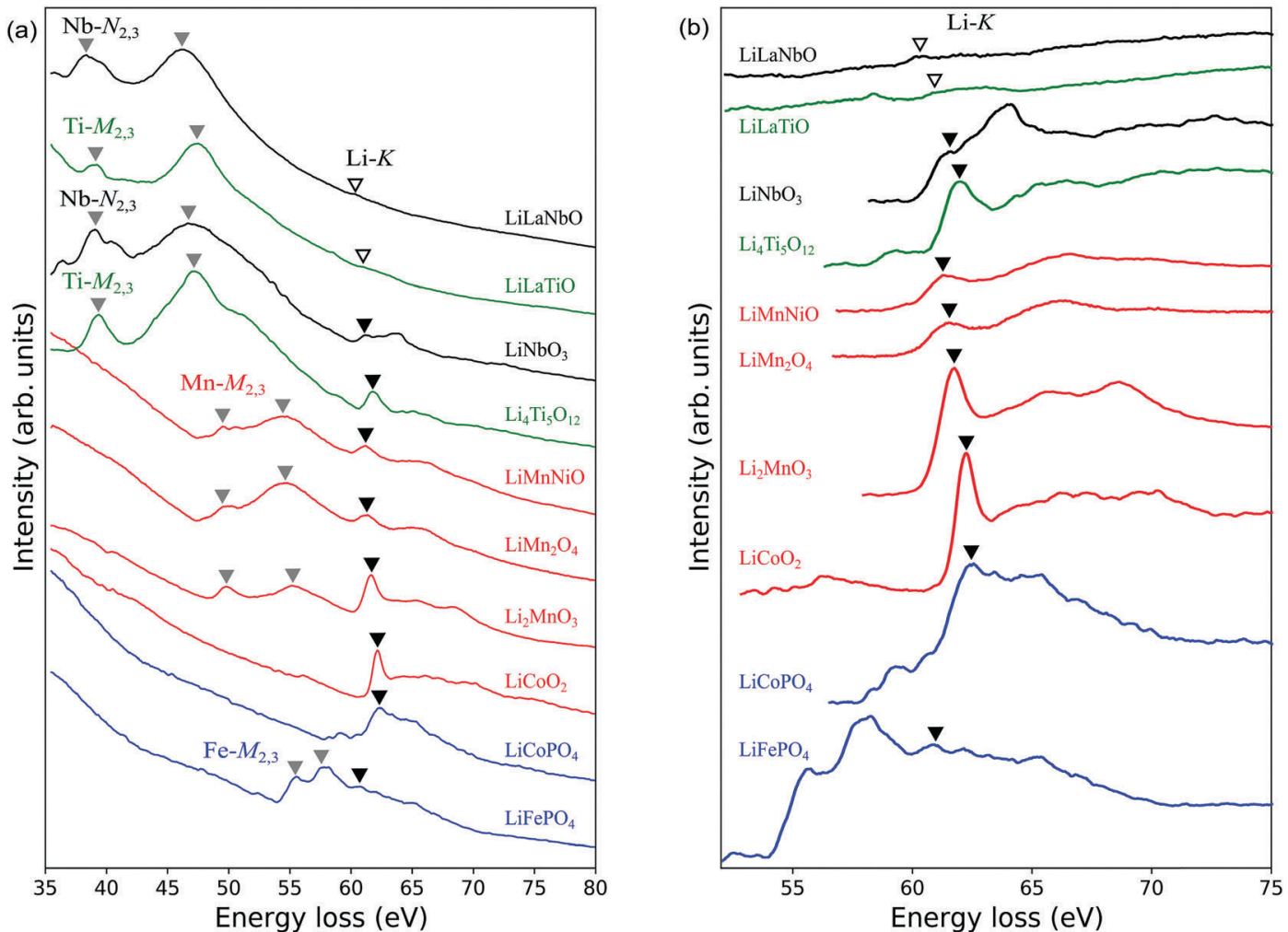

Fig. 3 EELS spectra of Li-ion battery materials: (a) comparison of total spectra from 10 materials; (b) magnified view of Li- $\mathrm{K}$ edges in the energy range 52 to $75 \mathrm{eV}$ after background subtraction. LiLaNbO, LiLaTiO and LiMnNiO stand for $\mathrm{Li}_{0.14} \mathrm{La}_{0.29} \mathrm{NbO}_{3}, \mathrm{Li}_{0.33} \mathrm{La}_{0.56} \mathrm{TiO}_{3}$ and $\mathrm{LiMn}_{1.5} \mathrm{Ni}_{0.5} \mathrm{O}_{4}$, respectively. Peaks of the TM edges $\left(\mathrm{M}_{2,3}\right.$ for $\mathrm{Mn}, \mathrm{Fe}, \mathrm{Co}, \mathrm{Ni}$ and $\mathrm{Ti} ; \mathrm{N}_{2,3}$ for $\mathrm{Nb}$ ) and the main peaks of $\mathrm{Li}-\mathrm{K}$ edges are indicated by grey and black inverted triangles, respectively. Open inverted triangles in the case of LLNO and LLTO indicate weak peaks assumed to be $\mathrm{Li}-\mathrm{K}$ edges. The tails of $\mathrm{Mn} / \mathrm{Fe}-\mathrm{M}_{2,3}$ edges overlap $\mathrm{Li}-\mathrm{K}$ edges, and $\mathrm{Co} / \mathrm{Ni}-\mathrm{M}_{2,3}$ edges merge completely with $\mathrm{Li}-\mathrm{K}$ edges. 
edges which also exist at around $60 \mathrm{eV},{ }^{34}$ so it is difficult to identify the Li-K edges with certainty. The chief reason for this is the lower Li concentrations in these solid electrolytes compared to the other materials; the volume densities of $\mathrm{Li}$ atoms in these two materials are approximately 2.3 and 5.7 atoms per $\mathrm{nm}^{3}$, respectively, while those of the other materials are between 13 and 40 atoms per $\mathrm{nm}^{3}$.

Previous studies of other Li-containing materials by ELNES or XANES showed that the positions of Li-K edges can vary by more than $5 \mathrm{eV}$ depending on the particular chemical environment of the Li atoms, as reflected in the Mulliken electronegativities or oxidation numbers of neighbouring atoms. ${ }^{18,63}$ In our work, the main Li-K peaks were observed to lie at around 61-62 eV for all materials except $\mathrm{Li}_{0.33} \mathrm{La}_{0.56} \mathrm{TiO}_{3}$ and $\mathrm{Li}_{0.14} \mathrm{La}_{0.29} \mathrm{NbO}_{3}$. This suggests that, although there are differences between the compounds, such as the $\mathrm{CN}$ of $\mathrm{Li}, \mathrm{Li}-\mathrm{O}$ bond lengths, and the types of second nearest neighbour cations, the positions of the main peaks are only slightly affected by the local environments around Li.

For some materials, the fine structures of Li-K edges contain small pre-edge peaks and/or sub-peaks above the main peak. These structures are expected to contain valuable information about the chemical bonding states in these compounds. It remains difficult, however, to extract these details because of the overlap with $\mathrm{TM}-\mathrm{M}_{2,3}$ edges mentioned above. Furthermore, although DFT calculations can help explicate these fine structures, simulation of a Li-K edge requires a calculation scheme that includes electron-hole coupling effects, e.g., the Bethe-Salpeter equation (BSE) method, ${ }^{64}$ which is beyond the scope of the present work.

\subsection{O-K ELNES}

Fig. 4 shows O-K ELNES spectra of the LIB materials examined in this study obtained with $\Delta E=0.3 \mathrm{eV}$. The peak positions occur at energies between $530 \mathrm{eV}$ and $550 \mathrm{eV}$. Based on the peak shapes, the materials can be categorised into the following three groups: (i) $\mathrm{Li}_{0.14} \mathrm{La}_{0.29} \mathrm{NbO}_{3}, \mathrm{Li}_{0.33} \mathrm{La}_{0.56} \mathrm{TiO}_{3}, \mathrm{LiNbO}_{3}$ and $\mathrm{Li}_{4} \mathrm{Ti}_{5} \mathrm{O}_{12}$, with double peaks split by a few electron-volts (indicated by inverted open triangles); (ii) $\mathrm{LiCoO}_{2}, \mathrm{Li}_{2} \mathrm{MnO}_{3}$, $\mathrm{LiMn}_{2} \mathrm{O}_{4}$ and $\mathrm{LiNi}_{0.5} \mathrm{Mn}_{1.5} \mathrm{O}_{4}$, with a single sharp, strong peak at the edge position (indicated by black inverted triangles); and (iii) $\mathrm{LiCoPO}_{4}$ and $\mathrm{LiFePO}_{4}$, with a single broad peak (indicated by grey inverted triangles). In Table 3 , the peak positions are listed for all ten materials and compared with available reported values. In all cases, differences in energy are less than $2 \mathrm{eV}$.

The observed trends can be partly interpreted in terms of the effect of TM-d orbitals overlapping with neighbouring O-2p orbitals. As reported in Table 1, TM atoms in group (i) materials have a $\mathrm{d}^{0}$ configuration, while TM atoms in the other two groups have partially occupied d orbitals. Since all TM atoms of the materials examined here are in octahedral coordination environments, their $\mathrm{d}$ orbitals are split into $\mathrm{t}_{2 \mathrm{~g}}$ and $\mathrm{e}_{\mathrm{g}}$ bands.

In group (i) materials, the $t_{2 g}$ and $e_{g}$ bands hybridise with unoccupied O-2p orbitals to form part of the conduction band. Such hybridisation results in splitting of the O-2p states into

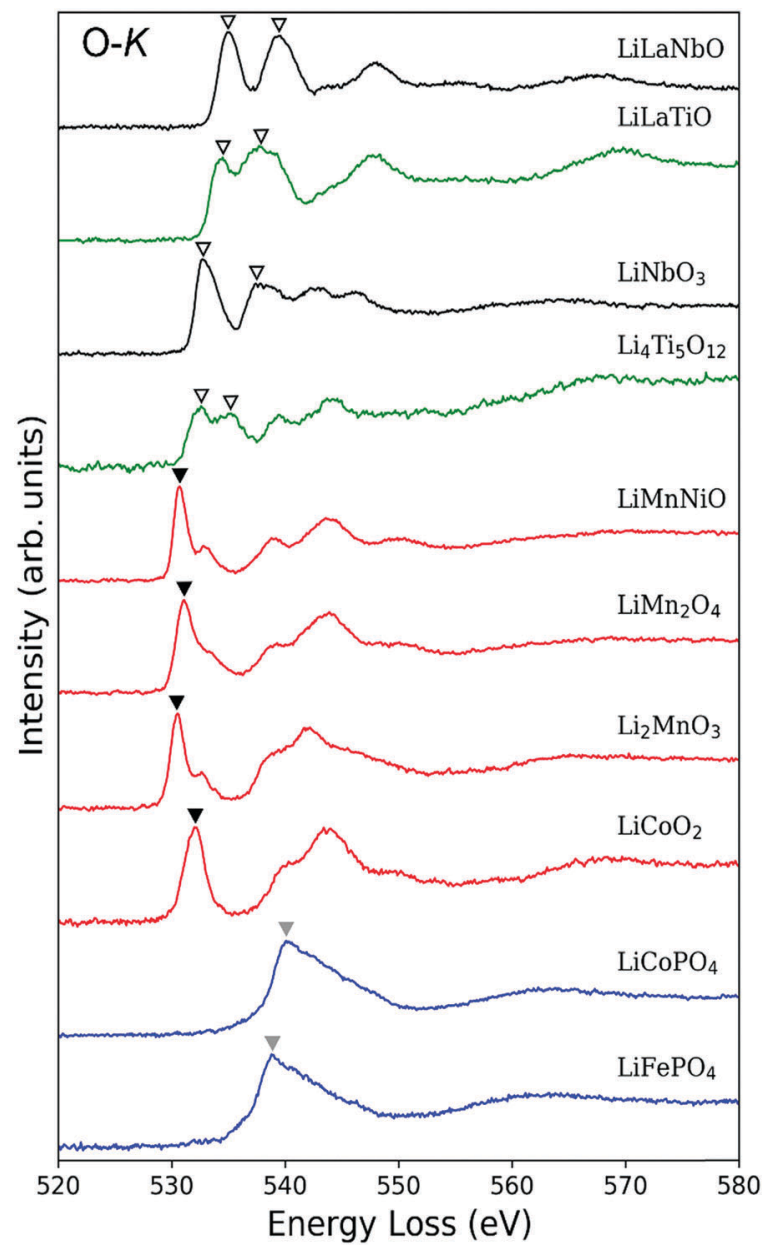

Fig. 4 EELS spectra around $\mathrm{O}-\mathrm{K}$ edges of the Li-ion battery materials. LiLaNbO, LiLaTiO and LiMnNiO stand for $\mathrm{Li}_{0.14} \mathrm{La}_{0.29} \mathrm{NbO}_{3}, \mathrm{Li}_{0.33} \mathrm{La}_{0.56} \mathrm{TiO}_{3}$ and $\mathrm{LiMn}_{1.5} \mathrm{Ni}_{0.5} \mathrm{O}_{4}$, respectively. Spectra can be classified into three groups according to edge shape: (i) double peaks of similar intensity (open inverted triangles); (ii) single sharp peak (black inverted triangles) with relatively weak sub-peak; and (iii) a single broad peak (grey inverted triangles).

Table 3 Peak positions and shapes of O-K edges compared with data in the literature

\begin{tabular}{llll}
\hline & \multicolumn{2}{l}{ O-K edge $(\mathrm{eV})$} & \\
\cline { 2 - 3 } Composition & This work & Previous work & Shape \\
\hline $\mathrm{LiFePO}_{4}$ & $\mathbf{5 3 8 . 7}$ & $537.0^{a}$ & Broad single \\
$\mathrm{LiCoPO}_{4}$ & $\mathbf{5 4 0 . 1}$ & $540.4^{b}$ & Broad single \\
$\mathrm{LiCoO}_{2}$ & $\mathbf{5 3 2 . 0}$ & $530.5^{c}$ & Sharp single \\
$\mathrm{Li}_{2} \mathrm{MnO}_{3}$ & $\mathbf{5 3 0 . 5}$ & $530.9^{d}$ & Sharp single \\
$\mathrm{LiMn}_{2} \mathrm{O}_{4}$ & $\mathbf{5 3 1 . 1}$ & $529.5^{e}$ & Sharp single \\
$\mathrm{LiNi}_{0.5} \mathrm{Mn}_{1.5} \mathrm{O}_{4}$ & $\mathbf{5 3 0 . 7}$ & & Sharp single \\
$\mathrm{Li}_{4} \mathrm{Ti}_{5} \mathrm{O}_{12}$ & $\mathbf{5 3 2 . 6 , 5 3 5 . 2}$ & $532.7,535.4^{f}$ & Double \\
$\mathrm{LiNbO}_{3}$ & $\mathbf{5 3 2 . 7}, \mathbf{5 3 7 . 8}$ & & Double \\
$\mathrm{Li}_{0.33} \mathrm{La}_{0.56} \mathrm{TiO}_{3}$ & $\mathbf{5 3 4 . 5 , 5 3 7 . 7}$ & $532.9,536.1^{g}$ & Double \\
$\mathrm{Li}_{0.14} \mathrm{La}_{0.29} \mathrm{NbO}_{3}$ & $\mathbf{5 3 5 . 1}, \mathbf{5 3 9 . 6}$ & & Double
\end{tabular}

${ }^{a}$ Ref. 35. ${ }^{b}$ Ref. 51. ${ }^{c}$ Ref. 30. ${ }^{d}$ Ref. 36. ${ }^{e}$ Ref. $14 .{ }^{f}$ Ref. 33. ${ }^{g}$ Ref. 34.

which an O-1s electron is excited, resulting in the double peak in the O-K ELNES spectra. 
In the case of group (ii) materials, the origin of the single sharp peak and small sub-peaks can also be explained in terms of the TM-d orbitals, with d orbitals in the conduction band splitting by different amounts as a result of their partial occupation (for details see Section S3 in ESI $\dagger$ ).

O-K ELNES spectra of group (iii) materials contain only one broad peak, and are distinctly different to those of group (ii) materials despite also containing partially occupied TM-d orbitals. In addition, the peak positions of group (iii) materials are energetically higher than those of the other groups. These differences cannot be explained satisfactorily using a simple model of the electronic structure, so we simulated the ELNES of a group (ii) material, $\mathrm{LiCoO}_{2}$, and a group (iii) material, $\mathrm{LiFePO}_{4}$, using the core-hole method within the framework of DFT, analysing and comparing their electronic structures in detail.

\subsection{O-K ELNES simulations of $\mathrm{LiCoO}_{2}$ and $\mathrm{LiFePO}_{4}$}

Fig. 5(a) shows experimental and simulated O-K ELNES spectra of $\mathrm{LiCoO}_{2}$ when $\Delta E=0.3 \mathrm{eV}$. The simulated spectrum matches the shape of the experimental spectrum well, as well as the calculated O-K X-ray absorption near edge structure. ${ }^{47,48}$ Fig. 5(b) shows PDOSs of O-p, Co-d and Li-p orbitals, with ground-state and excited-state PDOSs plotted as solid and dashed lines, respectively. The excited-state PDOSs are from the $\mathrm{O}$ atom containing the core hole in the case of the $\mathrm{O}-\mathrm{p}$ orbital, and from $\mathrm{Co}$ and $\mathrm{Li}$ atoms neighbouring the excited $\mathrm{O}$ atom in the case of Co-d and Li-p orbitals, respectively.

In ground-state $\mathrm{LiCoO}_{2}$, the valence band consists of Co-3d $\left(t_{2 g}\right)$ and $\mathrm{O}-2 \mathrm{p}$ orbitals and the conduction band of Co-3d $\left(\mathrm{e}_{\mathrm{g}}\right)$, O-2p and Li-2p orbitals. ${ }^{30,47}$ The octahedral environment of the Co atom causes Co-d orbitals to split into fully occupied $t_{2 g}$ states and unoccupied $\mathrm{e}_{\mathrm{g}}$ states. The calculated band gap of $2.5 \mathrm{eV}$ is consistent with previous DFT calculations. ${ }^{48}$

Formation of an O-1s hole reduces the symmetry reduction of $\mathrm{CoO}_{6}$ octahedra resulting in splitting of Co-d $\left(\mathrm{e}_{\mathrm{g}}\right)$ orbitals hybridised with $2 \mathrm{p}$ orbitals of the excited $\mathrm{O}$ atom. This splitting lowers the conduction band minimum by about $1.5 \mathrm{eV}$, resulting in a lowering of the energy of the O-K edge, and produces the very small shoulder-like sub-peak in the tail of the main peak in the ELNES. Other changes in the shape of the broad hybridisation band between $\mathrm{O}-2 \mathrm{p}$ and Li-2p orbitals at energies higher than $7 \mathrm{eV}$ in the excited state are also noticeable in the PDOS plots in Fig. 5(b). Since the O-K ELNES spectrum is produced by the transition of an O-1s electron to unoccupied O-p states, Fig. 5(b) shows that the single sharp ELNES peak at around $532 \mathrm{eV}$ and the broad peak at energies higher than $536 \mathrm{eV}$ originate from hybridisation of O-p orbitals with Co-d and Li-p orbitals, respectively.

Experimental and calculated O-K ELNES spectra of $\mathrm{LiFePO}_{4}$ using $\Delta E=0.3 \mathrm{eV}$ are compared in Fig. 6(a). Fig. 6(b) shows PDOSs of O-p, Fe-d, P-p and Li-p orbitals in ground and excited states in the same manner as for $\mathrm{LiCoO}_{2}$ in Fig. 5(b) where PDOSs of the excited $\mathrm{O}$ atom and $\mathrm{Fe}, \mathrm{P}$ and $\mathrm{Li}$ atoms neighbouring it have been averaged over contributions from crystallographically independent sites. (a)

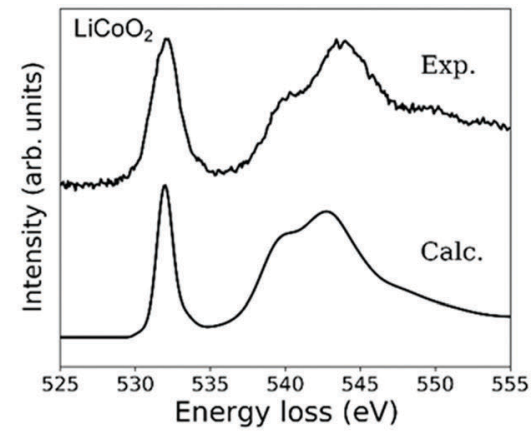

(b)

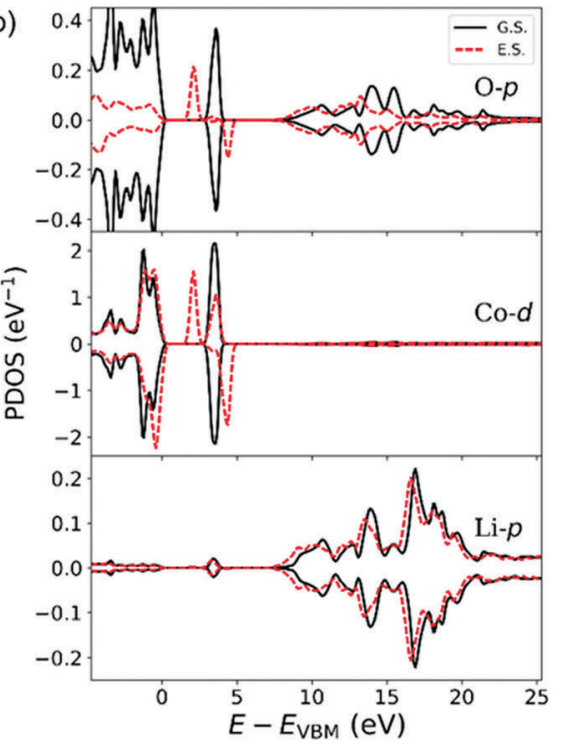

Fig. 5 (a) Experimental and calculated ELNES spectra of the O-K edge of $\mathrm{LiCOO}_{2}$ and (b) projected densities of states (PDOSs) of O-p, Co-d and Li-p orbitals in $\mathrm{LiCOO}_{2}$. Solid lines are PDOSs for the ground state (G.S.) and dashed lines are for the excited state (E.S.). PDOSs of Co and $\mathrm{Li}$ in the excited state were extracted from atoms neighbouring the excited $\mathrm{O}$ atom.

The calculated O-K ELNES spectrum in Fig. 6(a) has a single broad peak and appears more similar to the experimental spectrum compared to those previously calculated using the $Z+1$ method $^{19}$ or from dielectric function calculations. ${ }^{20}$ This result demonstrates the efficacy of using the core-hole method to simulate the ELNES spectra with reasonable accuracy. ${ }^{62}$

In the ground state, while the top of the valence band of $\mathrm{LiFePO}_{4}$ consists of $\mathrm{O}-2 \mathrm{p}$ and $\mathrm{Fe}-3 \mathrm{~d}$ orbitals, in the energy range from 3 to $5 \mathrm{eV}$ above the valence band maximum (VBM), the conduction band mainly consists of $\mathrm{O}-2 \mathrm{p}$ and $\mathrm{Fe}-3 \mathrm{~d}$ orbitals and the region with energies higher than $5 \mathrm{eV}$ consists of O-p, P-p and Li-p orbitals (Fig. 6(b)). The relatively large differences between up- and down-spin contributions in PDOSs of Fe-d and O-p orbitals reflect the high-spin states of $\mathrm{Fe}^{2+}$ ions with a d $\mathrm{d}^{6}$ electronic configuration, i.e., $\left(\mathrm{t}_{2 \mathrm{~g}}\right)^{4}\left(\mathrm{e}_{\mathrm{g}}\right)^{2}$. The observed broad distribution of the O-p PDOS in the conduction band is a result of hybridisation between $\mathrm{O}-\mathrm{p}$ orbitals and neighbouring $\mathrm{Fe}, \mathrm{P}$ and Li orbitals. This overlapping of several orbitals in the conduction band is characteristic of $\mathrm{LiFePO}_{4}$, in contrast to the clear separation between hybrid O-Co and $\mathrm{Li}-\mathrm{O}$ orbitals in the conduction band of $\mathrm{LiCoO}_{2}$. 
(a)

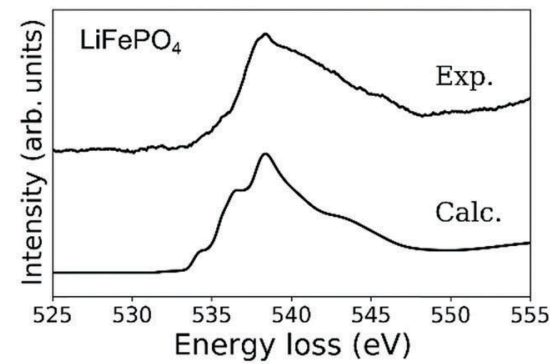

(b)
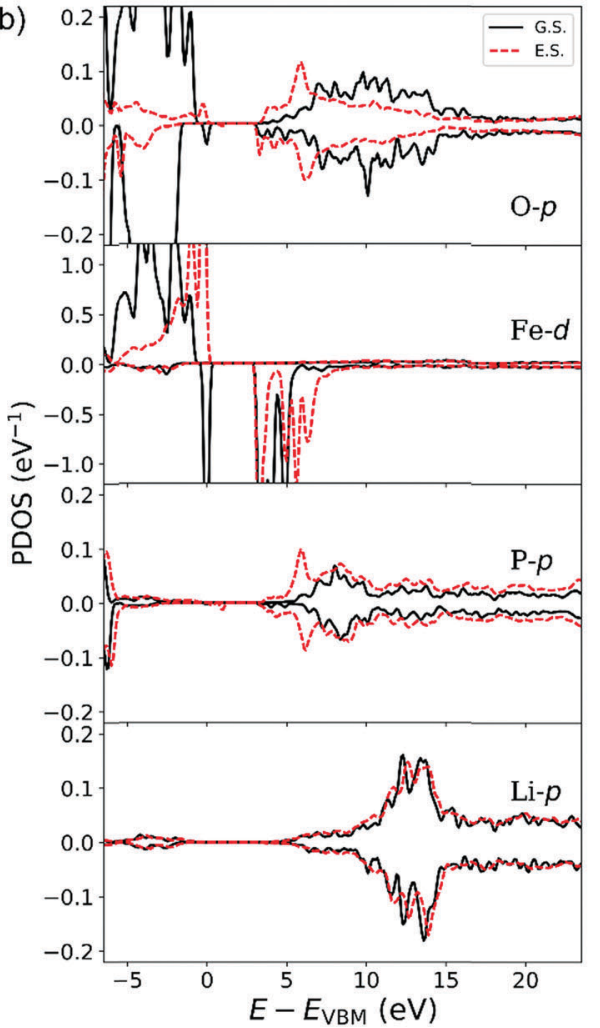

Fig. 6 (a) Experimental and calculated ELNES spectra of the $O-K$ edge of $\mathrm{LiFePO}_{4}$ and (b) projected densities of states (PDOSs) of O-p, Fe-d, P-p and $\mathrm{Li}-\mathrm{p}$ orbitals in $\mathrm{LiFePO}_{4}$. Solid lines are PDOSs for the ground state (G.S.) and dashed lines are for the excited state (E.S.). PDOSs of Fe, P and Li in the excited state were extracted from atoms neighbouring the excited $O$ atom. Calculated O-p PDOSs and ELNES spectra are averages of data from $\mathrm{O}$ atoms on the three non-equivalent crystallographic sites in the olivine-type structure.

When an electron is elevated from an O-1s shell in $\mathrm{LiFePO}_{4}$, the PDOSs of O-p, Fe-d and P-p orbitals at the bottom of the conduction band (around 3 to $7 \mathrm{eV}$ above the VBM) change dramatically, while their PDOSs at higher energies undergo relatively little change. Introduction of the core hole shifts the bottom of the conduction band, which in the ground state consists mainly of Fe-d electrons between 3 and $5 \mathrm{eV}$ above the VBM, higher by about $1.5 \mathrm{eV}$. The PDOS of P-p orbitals between 5 and $7 \mathrm{eV}$ above the Fermi level also increases dramatically, a consequence of the strong covalent bonding between $\mathrm{P}$ and $\mathrm{O}$ atoms. The band gap, however, remains essentially unchanged because Fe-d orbitals at the top of the valence band in the ground state are elevated to the bottom of the conduction band in the excited state. These changes enhance the energetic overlap between the $\mathrm{Fe}-\mathrm{O}$, $\mathrm{Li}-\mathrm{O}$ and $\mathrm{P}-\mathrm{O}$ hybrid orbitals, resulting in the characteristic broad peak in the O-K ELNES of $\mathrm{LiFePO}_{4}$, in contrast to that of $\mathrm{LiCoO}_{2}$. The broad single peaks observed for group (iii) materials $\left(\mathrm{LiFePO}_{4}\right.$ and $\left.\mathrm{LiCoPO}_{4}\right)$ can thus be attributed to the presence of tetrahedral $\mathrm{PO}_{4}$ units in addition to the TM-O polyhedra. Group (ii) materials, which lack $\mathrm{PO}_{4}$ tetrahedral units, exhibit single, sharp O-K edges regardless of the overall crystal structure, e.g., layered-rocksalt in the case of $\mathrm{LiCoO}_{2}$ or spinel in the case of $\mathrm{LiMn}_{2} \mathrm{O}_{4}$.

Although the band gaps of $\mathrm{LiCoO}_{2}$ and $\mathrm{LiFePO}_{4}$ are almost the same, the peak positions of $\mathrm{O}-\mathrm{K}$ edges in $\mathrm{LiCoO}_{2}$ and $\mathrm{LiFePO}_{4}$ differ by about $6.7 \mathrm{eV}$. Our ELNES simulations also demonstrated a similar trend, with a calculated difference in peak positions of $4.9 \mathrm{eV}$. Analysis of the electronic structures showed that this difference arises from the difference in changes in the conduction bands in the excited state. As mentioned above, the peak in the O-K edge of $\mathrm{LiCoO}_{2}$ corresponds to the conduction band minimum composed of hybrid O-Co orbitals, and decreases by about $1.5 \mathrm{eV}$ upon introduction of a core hole. In the case of $\mathrm{LiFePO}_{4}$, the conduction band minimum is not decreased when a core hole is introduced, and neither are there isolated hybrid $\mathrm{O}-\mathrm{TM}$ orbitals. This difference provides one explanation for why the main peak of the $\mathrm{O}-\mathrm{K}$ edge in $\mathrm{LiFePO}_{4}$ appears at higher energy than in $\mathrm{LiCoO}_{2}$.

\section{Conclusions}

Li-K and O-K ELNES spectra of ten different representative LIB materials were systematically investigated by EELS using an aberration-corrected TEM equipped with a monochromator. Measurements with a high energy resolution of $\Delta E=0.1 \mathrm{eV}$ revealed fine structures in Li-K ELNES spectra that can otherwise remain hidden. The peak positions of Li-K edges were found to be about $62 \mathrm{eV}$ for most of the LIB materials because of the similar coordination environments of their Li ions. In contrast, the peak positions of O-K edges varied over a range of about $10 \mathrm{eV}$.

The shapes of O-K edges could be divided into three groups. Group (i) materials contained octahedrally coordinated TM ions with empty d orbitals, and these materials produced ELNES with double peaks at the O-K edges because of splitting of TM-d orbitals into $t_{2 g}$ and $e_{g}$ levels. Group (ii) and (iii) materials both contained TM ions with partially filled d orbitals, but the shapes of their O-K edges were found to be distinctly different, the former with a single sharp peak and the latter with a single broad peak.

ELNES simulations based on DFT revealed that the single sharp peak in the O-K edge of group (ii) material $\mathrm{LiCoO}_{2}$ results from hybridisation of O-p and Co-d e $e_{g}$ orbitals with energies close to the conduction band minimum. In contrast, the broad peak of the O-K edge of group (iii) material $\mathrm{LiFePO}_{4}$ results from hybridisation between O-p orbitals with P-p, Fe-d and Li-p orbitals in the conduction band at similar energy levels.

Our systematic analysis of EELS spectra demonstrates how a combination of high-resolution ELNES measurements and 
simulations based on DFT calculations provides useful insights into the electronic structures and coordination environments of atoms in LIB materials.

\section{Conflicts of interest}

There are no conflicts to declare.

\section{Acknowledgements}

This work was partially supported by the Research \& Development Initiative for Scientific Innovation of New Generation Batteries 2 (RISING 2) project from the New Energy and Industrial Technology Development Organization (NEDO), Japan. The authors thank Toyota Motor Corporation for providing some of the samples.

\section{References}

1 J. M. Tarascon and M. Armand, Nature, 2001, 414, 359-367. 2 M. S. Whittingham, Chem. Rev., 2004, 104, 4271-4301.

3 J. B. Goodenough and Y. Kim, Chem. Mater., 2010, 22, 587-603.

4 C. Sun, J. Liu, Y. Gong, D. P. Wilkinson and J. Zhang, Nano Energy, 2017, 33, 363-386.

5 P. E. Batson, Ultramicroscopy, 1992, 47, 133-144.

6 K. Suenaga, Science, 2000, 290, 2280-2282.

7 S. Muto and K. Tatsumi, Microscopy, 2016, 1-11.

8 K. J. Carroll, D. Qian, C. Fell, S. Calvin, G. M. Veith, M. Chi, L. Baggetto and Y. S. Meng, Phys. Chem. Chem. Phys., 2013, 15, 11128-11138.

9 R. Senga and K. Suenaga, Nat. Commun., 2015, 6, 7943.

10 W. Zhou, M. P. Oxley, A. R. Lupini, O. L. Krivanek, S. J. Pennycook and J.-C. Idrobo, Microsc. Microanal., 2012, 18, 1342-1354.

11 T. Mizoguchi, T. Sasaki, S. Tanaka, K. Matsunaga, T. Yamamoto, M. Kohyama and Y. Ikuhara, Phys. Rev. B: Condens. Matter Mater. Phys., 2006, 74, 1-10.

12 R. Huang, Y. H. Ikuhara, T. Mizoguchi, S. D. Findlay, A. Kuwabara, C. A. J. Fisher, H. Moriwake, H. Oki, T. Hirayama and Y. Ikuhara, Angew. Chem., Int. Ed., 2011, 50, 3053-3057.

13 R. F. Egerton, Electron Energy-Loss Spectroscopy in the Electron Microscope, Springer, US, Boston, MA, 3rd edn, 2011.

14 X. Gao, Y. H. Ikuhara, C. A. J. Fisher, H. Moriwake, A. Kuwabara, H. Oki, K. Kohama, R. Yoshida, R. Huang and Y. Ikuhara, Adv. Mater. Interfaces, 2014, 1, 1400143.

15 R. Huang, T. Hitosugi, C. A. J. Fisher, Y. H. Ikuhara, H. Moriwake, H. Oki and Y. Ikuhara, Mater. Chem. Phys., 2012, 133, 1101-1107.

16 L. Laffont, C. Delacourt, P. Gibot, M. Y. Wu, P. Kooyman, C. Masquelier and J. M. Tarascon, Chem. Mater., 2006, 18, 5520-5529.

17 T. Mizoguchi, J. P. Buban, K. Matsunaga, T. Yamamoto and Y. Ikuhara, Ultramicroscopy, 2006, 106, 92-104.

18 F. Wang, J. Graetz, M. S. Moreno, C. Ma, L. Wu, V. Volkov and Y. Zhu, ACS Nano, 2011, 5, 1190-1197.
19 S. C. Nagpure, S. S. S. Babu, B. Bhushan, A. Kumar, R. Mishra, W. Windl, L. Kovarik and M. Mills, Acta Mater., 2011, 59, 6917-6926.

20 M. K. Kinyanjui, P. Axmann, M. Wohlfahrt-Mehrens, P. Moreau, F. Boucher and U. Kaiser, J. Phys.: Condens. Matter, 2010, 22, 275501.

21 K. Kimoto and Y. Matsui, J. Microsc., 2002, 208, 224-228.

22 P. C. Tiemeijer, Inst. Phys. Conf. Ser., 1999, 161, 191.

23 M. Mukai, J. S. Kim, K. Omoto, H. Sawada, A. Kimura, A. Ikeda, J. Zhou, T. Kaneyama, N. P. Young, J. H. Warner, P. D. Nellist and A. I. Kirkland, Ultramicroscopy, 2014, 140, 37-43.

24 M. Mukai, E. Okunishi, M. Ashino, K. Omoto, T. Fukuda, A. Ikeda, K. Somehara, T. Kaneyama, T. Saitoh, T. Hirayama and Y. Ikuhara, Microscopy, 2015, 64, 151-158.

25 Z. Wang, D. Santhanagopalan, W. Zhang, F. Wang, H. L. Xin, K. He, J. Li, N. Dudney and Y. S. Meng, Nano Lett., 2016, 16, 3760-3767.

26 N. Taguchi, H. Sakaebe, K. Tatsumi and T. Akita, e-J. Surf. Sci. Nanotechnol., 2015, 13, 284-288.

27 X. Mu, A. Kobler, D. Wang, V. S. K. K. Chakravadhanula, S. Schlabach, D. V. Szabó, P. Norby and C. Kübel, Ultramicroscopy, 2016, 170, 10-18.

28 S. Kobayashi, C. A. J. Fisher, T. Kato, Y. Ukyo, T. Hirayama and Y. Ikuhara, Nano Lett., 2016, 16, 5409-5414.

29 P. Yan, L. Xiao, J. Zheng, Y. Zhou, Y. He, X. Zu, S. X. Mao, J. Xiao, F. Gao, J.-G. Zhang and C.-M. Wang, Chem. Mater., 2015, 27, 975-982.

30 J. Kikkawa, S. Terada, A. Gunji, M. Haruta, T. Nagai, K. Kurashima and K. Kimoto, Appl. Phys. Lett., 2014, 104, 114105.

31 J. Graetz, A. Hightower, C. C. Ahn, R. Yazami, P. Rez and B. Fultz, J. Phys. Chem. B, 2002, 106, 1286-1289.

32 P. Moreau and F. Boucher, Micron, 2012, 43, 16-21.

33 M. Kitta, T. Akita, S. Tanaka and M. Kohyama, J. Power Sources, 2013, 237, 26-32.

34 C. Ma, K. Chen, C. Liang, C.-W. Nan, R. Ishikawa, K. More and M. Chi, Energy Environ. Sci., 2014, 7, 1638.

35 Y. Honda, S. Muto, K. Tatsumi, H. Kondo, K. Horibuchi, T. Kobayashi and T. Sasaki, J. Power Sources, 2015, 291, 85-94.

36 J. Kikkawa, T. Akita, E. Hosono, H. Zhou and M. Kohyama, J. Phys. Chem. C, 2010, 114, 18358-18365.

37 K. Mizushima, P. Jones, P. Wiseman and J. Goodenough, Solid State Ionics, 1981, 3-4, 171-174.

38 A. K. Padhi, K. S. S. Nanjundaswamy and J. B. Goodenough, J. Electrochem. Soc., 1997, 144, 1188-1194.

39 M. M. Thackeray, W. I. F. David, P. G. Bruce and J. B. Goodenough, Mater. Res. Bull., 1983, 18, 461-472.

40 G. G. Amatucci, N. Pereira, T. Zheng and J.-M. Tarascon, J. Electrochem. Soc., 2001, 148, A171.

41 A. Yamada, S. C. Chung and K. Hinokuma, J. Electrochem. Soc., 2001, 148, A224.

42 L.-X. Yuan, Z.-H. Wang, W.-X. Zhang, X.-L. Hu, J.-T. Chen, Y.-H. Huang and J. B. Goodenough, Energy Environ. Sci., 2011, 4, 269-284.

43 J. M. Lloris, C. Pérez Vicente and J. L. Tirado, Electrochem. Solid-State Lett., 2002, 5, A234. 
44 F. Zhou, M. Cococcioni, K. Kang and G. Ceder, Electrochem. Commun., 2004, 6, 1144-1148.

45 Q. Zhong, A. Bonakdarpour, M. Zhang, Y. Gao, J. R. Dahn, A. Bonakclarpour, M. Zhang, Y. Gao and J. R. Dahn, J. Electrochem. Soc., 1997, 144, 205.

46 K. Zhang, X. Han, Z. Hu, X. Zhang, Z. Tao and J. Chen, Chem. Soc. Rev., 2015, 44, 699-728.

47 M. T. Czyzyk, R. Potze and G. A. Sawatzky, Phys. Rev. B: Condens. Matter Mater. Phys., 1992, 46, 3729-3735.

48 A. Juhin, F. de Groot, G. Vankó, M. Calandra and C. Brouder, Phys. Rev. B: Condens. Matter Mater. Phys., 2010, 81, 1-12.

49 G. Rousse, J. Rodriguez-Carvajal, S. Patoux and C. Masquelier, Chem. Mater., 2003, 15, 4082-4090.

50 A. Nakamura, S. Furutsuki, S. Nishimura, T. Tohei, Y. Sato, N. Shibata, A. Yamada and Y. Ikuhara, Chem. Mater., 2014, 26, 6178-6184.

51 Y. H. Ikuhara, X. Gao, C. A. J. Fisher, A. Kuwabara, H. Moriwake, K. Kohama, H. Iba and Y. Ikuhara, J. Mater. Chem. A, 2017, 5, 9329-9338.

52 Y. H. Ikuhara, X. Gao, R. Huang, C. A. J. Fisher, A. Kuwabara, H. Moriwake and K. Kohama, J. Phys. Chem. C, 2014, 118, 19540-19547.

53 A. Kumatani, S. Shiraki, Y. Takagi, T. Suzuki, T. Ohsawa, X. Gao, Y. Ikuhara and T. Hitosugi, Jpn. J. Appl. Phys., 2014, 53, 058001.
54 Y. Fujiwara, K. Hoshikawa and K. Kohama, J. Cryst. Growth, 2016, 433, 48-53.

55 X. Gao, C. A. J. Fisher, T. Kimura, Y. H. Ikuhara, H. Moriwake, A. Kuwabara, H. Oki, T. Tojigamori, R. Huang and Y. Ikuhara, Chem. Mater., 2013, 25, 1607-1614.

56 M. O. Krause, J. Phys. Chem. Ref. Data, 1979, 8, 307-327.

57 V. I. Anisimov, J. Zaanen and O. K. Andersen, Phys. Rev. B: Condens. Matter Mater. Phys., 1991, 44, 943-954.

58 J. P. Perdew, K. Burke and M. Ernzerhof, Phys. Rev. Lett., 1996, 77, 3865-3868.

59 F. Zhou, M. Cococcioni, C. A. Marianetti, D. Morgan and G. Ceder, Phys. Rev. B: Condens. Matter Mater. Phys., 2004, 70, 235121.

60 G. Kresse and J. Furthmüller, Phys. Rev. B: Condens. Matter Mater. Phys., 1996, 54, 11169-11186.

61 G. K. H. H. Madsen, P. Blaha, K. Schwarz, E. Sjöstedt and L. Nordström, Phys. Rev. B: Condens. Matter Mater. Phys., 2001, 64, 195134.

62 T. Mizoguchi, W. Olovsson, H. Ikeno and I. Tanaka, Micron, 2010, 41, 695-709.

63 J. Tsuji, H. Nakamatsu, T. Mukoyama, K. Kojima, S. Ikeda and K. Taniguchi, X-Ray Spectrom., 2002, 31, 319-326.

64 W. Olovsson, I. Tanaka, T. Mizoguchi, P. Puschnig and C. Ambrosch-Draxl, Phys. Rev. B: Condens. Matter Mater. Phys., 2009, 79, 041102. 